\title{
Metals Foams for Biomedical Aplications: Processing and Mechanical Properties
}

\author{
MUSTAFA GUDEN ${ }^{*}, \dagger$, EMRAH ÇELIK $^{\ddagger}$, SINAN ÇETINER $^{\#}$ and \\ ALPTEKIN AYDIN $^{\#}$ \\ ${ }^{*}$ Department of Mechanical Engineering, ${ }^{\dagger}$ Center for Materials Research, ${ }^{\ddagger}$ Materials Science \\ and Engineering Program, Izmir Institute of Technology, Gulbahce Koyu, Urla, Izmir, \\ TURKEY; "Hipokrat A.Ş., 407/6 Sok., No:10, Pınarbaşı, Izmir, TURKEY
}

\section{INTRODUCTION}

Optimized structures found in nature can be sometimes imitated in engineering structures. The recent interest in functionally graded metallic materials makes bone structures interesting because bones are naturally functionally graded ${ }^{1}$. The cellular structure of foam metals (Fig.1) is very similar to that of the cancellous bone; therefore, these metals can be considered as potential candidates for future implant applications if porosity level, size and shape, strength and biocompatibility aspects satisfy the design specifications of implants. Foam metals based on biocompatible metallic materials (e.g. Ti and Ti-6Al-4V) are expected to provide better interaction with bone. This is mainly due to higher degree of bone growth into porous surfaces and higher degree of body fluid transport through three-dimensional interconnected array of pores ${ }^{2}$ (open cell foam), leading to better interlocking between implant and bone and hence reducing or avoiding the well-known implant losening. Furthermore, the elastic modulus of foam metals can be easily tailored with porosity level to match that of natural bone, leading to a better performance by avoiding the high degree of elastic mismatch which currently exists between conventional solid metallic implants and bone.

Foaming of metals is a complicated process in which a large number of processing and geometrical parameters have to be adjusted adequately. 
Currently, no complete, theoretically based understanding of all details of the foaming process has been developed. However, a set of empirical rules have been worked out that allow the production of foam metal components of a considerable quality and complexity. This has been achieved particularly for aluminium alloys ${ }^{3}$ and manufacturing technology still needs considerable research effort for the processing of implant grade materials.

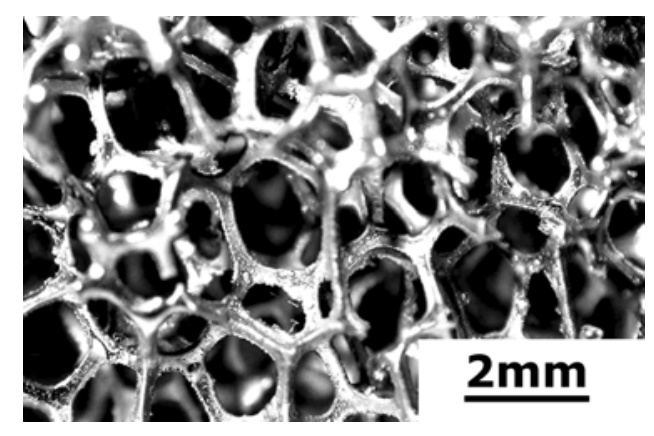

Figure 1. The cellular structure of open cell Ni foam.

\section{PROCESSING ROUTE OF IMPLANT FOAM METALS}

There are two basic approaches currently available for the manufacture of foam metals: melting and powder metallurgy $(\mathrm{PM})^{4}$. Designed structures are commercially manufactured via continuous or batch type casting methods, e.g. cell forming mould removal method used by DUOCEL for the production of open cell $\mathrm{Al}$ and $\mathrm{Al}$ alloy foams ${ }^{4}$. Self forming structures are manufactured either by gas injection through (CYMAT/HYDRO) or gas forming element addition (ALPOROS) into liquid metal ${ }^{4}$. Although, melting methods have been successfully applied to the manufacture of $\mathrm{Al}, \mathrm{Zn}$ and $\mathrm{Mg}$ foams, they are not suitable for the manufacture of Ti foams due to the high melting temperature and reactivity of Ti. In the PM approach, designed structures are manufactured either by sintering of hollow spheres or by melting or partial melting of powder compacts that contain a gas evolving element (e.g. $\left.\mathrm{TiH}_{2}\right)^{3}$. Since these methods unavoidably result in enclosed pores (closed cell foam), they are also not suitable for the manufacture of foamed metal implants because of the requirement of body fluid transport. Open cell implant foam metals can be however successfully manufactured by a versatile PM based process known as space holder method ${ }^{5-7}$. The method can be used to manufacture fully and/or partially (as coatings on 
solid implants for bone fixation) foamed biomedical metals. The size, level and geometry of pores can be easily altered by varying the size, amount and shape of space holder. Therefore, it is one of the appropriate methods for manufacturing designed foam metal implants.

The processing steps of space holder method are schematically presented in Fig. 2. The process starts with mixing of metal powders with a suitable space holder material, followed by a compaction step (e.g. uniaxial and isostatic pressing) that produces metal powder-space holder mixture compact. The green compact is then heat treated at a relatively low temperature to release the space holder, resulting in an unfired open cell foam metal structure. Finally, the compact is sintered at relatively high temperatures to provide structural integrity. This method allows a direct near net-shape fabrication of foamed implant components with a relatively homogeneous pore structure and a high level of porosity (60-80\%).

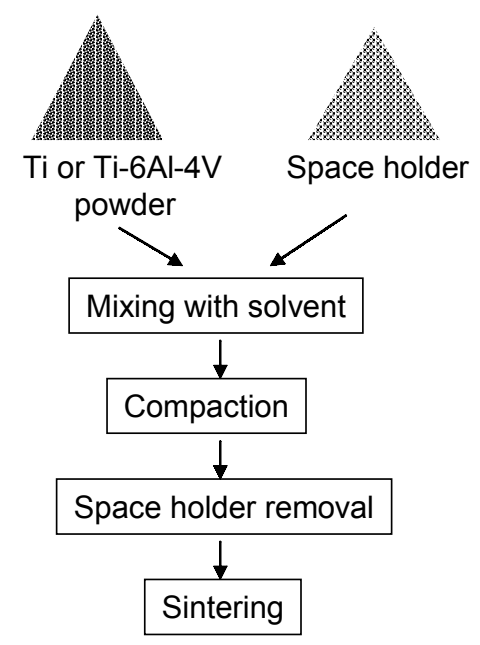

Figure 2. Processing steps of space holder method.

Ti and its alloys are known to be very reactive and can easily form interstitial solid solutions with other elements including carbon, oxygen and nitrogen. Since the presence of these elements is detrimental for the ductility, the reaction between Ti powder and the cracking products of the space holder in a temperature range of $300-600{ }^{\circ} \mathrm{C}$ must be avoided ${ }^{5,8}$. It is therefore proposed that space holder should be removed at temperatures below about $200{ }^{\circ} \mathrm{C}^{5}$. Ammonium hydrogen carbonate and carbamide (urea) are the materials identified to satisfy this criterion and currently used for the processing of Ti foams ${ }^{5-7}$. 
The optimum pore size range required for the attachment and proliferation of new bone tissue and the transport of body fluids is given to be between 200 and $500 \mu \mathrm{m}^{9}$; therefore, the particle size range of space holder must be selected and/or tailored according to the critical pore size range. In the design of foam metal final pore size range, however, pore shrinkage occurring during sintering should also be taken into consideration. For the preparation of highly porous foam parts, the particle size distribution of metal powder should be lower than the average particle size of space holder ${ }^{5}$. A particle size lower than $150 \mu \mathrm{m}$ is normally sufficient for the homogeneous coating of $200-500 \mu \mathrm{m}$ size space holder particles with $\mathrm{Ti}$ powder. Furthermore, the consolidation pressure of metal powder-space holder mixture must be high enough for the preparation of mechanically strong compacts that would retain their geometry throughout the foaming process. The compaction of Ti powder is usually conducted under a uniaxial pressure ranging between 100 and $200 \mathrm{MPa}$, while higher pressures, or a binder material, may be required for the compaction of the harder Ti-6Al-4V powder.

Using the space holder method, Ti and Ti-6Al-4V foam metals with 60 and $70 \%$ porosities were prepared and microscopically and mechanically characterized in our laboratory. Ti foams were prepared using angular $\mathrm{Ti}$ powder $(<45 \mu \mathrm{m})$ and ammonium hydrogen carbonate (angular, 200-500 $\mu \mathrm{m})$ as space holder. Compaction was performed by applying a uniaxial pressure of $200 \mathrm{MPa}$ inside a cylindrical steel die $(25 \mathrm{~mm}$ in diameter). The compacts were heat treated at $200{ }^{\circ} \mathrm{C}$ for $5 \mathrm{~h}$ to remove the space holder and then sintered at $1250{ }^{\circ} \mathrm{C}$ for $2 \mathrm{~h}$. Figs. $3 \mathrm{a}-\mathrm{c}$ show the microstructures of the $\mathrm{Ti}$ foams at various magnifications. Two different pore size ranges, macro$(200-500 \mu \mathrm{m})$ and micro- $(1-10 \mu \mathrm{m})$, are clearly seen in Figs. $3 \mathrm{~b}$ and $3 \mathrm{c}$, an observation which was also made previously in Ti foams prepared by the same method ${ }^{7}$. Micropores are located at the cell walls (Fig. 3b), between the sintered Ti powders, and are proposed to be a result of volume shrinkage of the powder during sintering 7 . Micropores and rough cell wall surfaces were reported to be preferable in osteoinductivity ${ }^{10}$.

Typical microstructures of prepared Ti-6Al-4V foams are shown in Figs. $4 \mathrm{a}$ and $4 \mathrm{~b}$. Ti-6Al-4V foams were prepared using the same method except the angular Ti-6Al-4V powder used $(<150 \mu \mathrm{m})$ that was compacted at a higher pressure, $400 \mathrm{MPa}$. Similar to Ti foams, micropores are also seen at the cell walls (Fig.4a). Due to the compaction pressure, the cells of the foams are observed to be preferentially aligned in the direction normal to the pressure direction, leading to an anisotropy in foam mechanical properties. The cell alignment, however, is more pronounced in Ti-6Al-4V foams because of the higher compaction pressure (Fig 4b). 


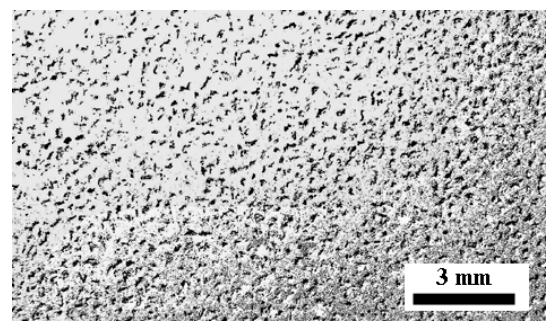

(a)

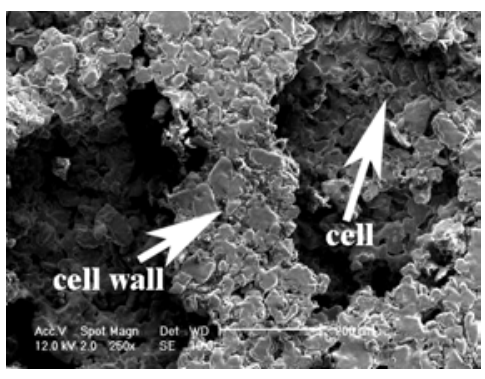

(b)

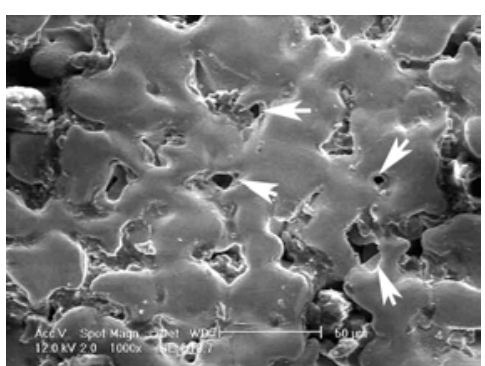

(c)

Figure 3. Scanning electron micrographs of $\mathrm{Ti}$ foam (70\% porous) showing a) cell structure, b) cell wall and cell, and c) micropores at cell wall.

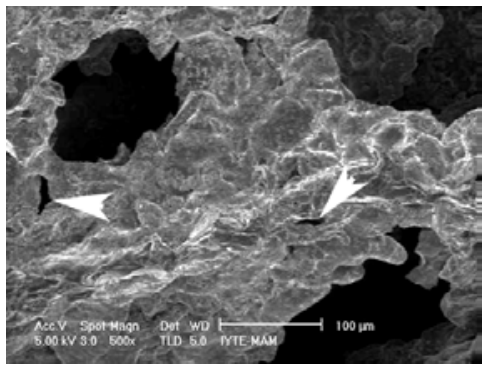

(a)

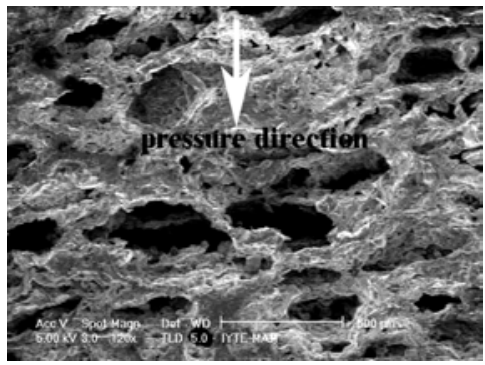

(b)

Figure 4. Scanning electron micrographs of Ti-6Al-4V foam (70\% porous) of showing a) cell wall micropores, and b) cell alignment.

\section{MECHANICAL PROPERTIES}

Under compressive loads, open and closed cell metal foams show a similar, characteristic stress-strain curve composed of three distinct deformation regions ${ }^{11}$ : linear elastic, plateau or collapse and densification as 
depicted in Fig. 5 for an Al closed cell foam. In the linear elastic region deformation is controlled by cell wall bending. This region is followed by a plateau or collapse region of cell wall bending and/or crushing. The onset of localization of deformation is called collapse stress (Fig. 5). Deformation is highly localized in the plateau region by the formation of a deformation band which proceeds to the undeformed regions of the sample as the strain increases. The plateau region is characterized by a plateau stress either with a constant value or increasing with increasing strain as the relative density increases. After a critical strain $\left(\varepsilon_{\mathrm{d}}\right)$ the material densifies, hence the stress increases sharply and approaches the strength of the bulk metal (densification region).

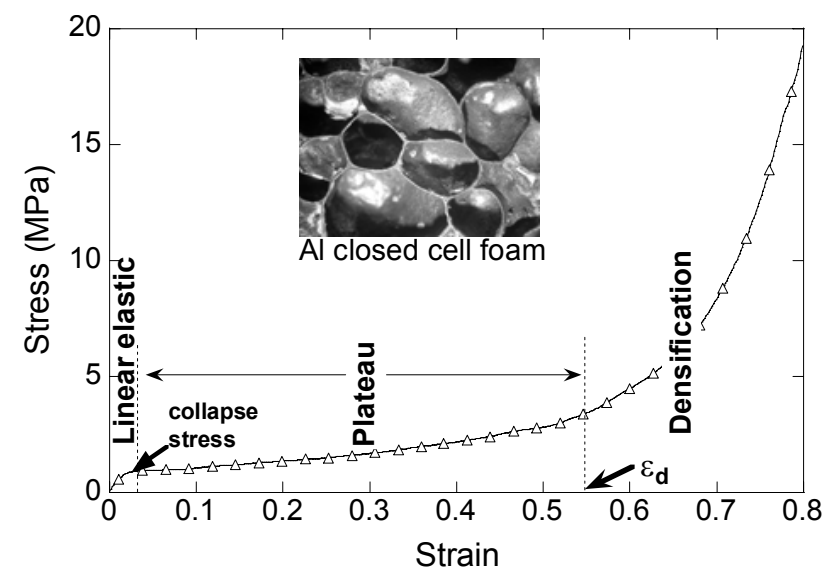

Figure 5. Compression stress-strain curve of an $\mathrm{Al}$ closed cell foam of $90 \%$ porosity (average cell size $3 \mathrm{~mm})^{12}$.

Ti and Ti-6Al-4V foams also show deformation behaviour similar to that of conventional $\mathrm{Al}$ foams. The compression stress-strain curves of $\mathrm{Ti}$ and $\mathrm{Ti}-$ 6Al-4V foams with 60 and $70 \%$ porosities are shown in Fig. 6 . In the figure, $\mathrm{N}$ and $\mathrm{P}$ refer to the compression test axis: testing parallel (P) and normal (N) to the applied pressure direction. The higher plateau stress values of $70 \%$ porous $\mathrm{Ti}$ foam tested in $\mathrm{N}$-direction are mainly due to the cell alignment as explained in the previous section. Preliminary results have also shown that Ti-6Al-4V foam shows higher stress values than $\mathrm{Ti}$ foam at the same porosity level (Fig. 6). The elastic modulus of the tested foams was further found to be in the range 4-10 GPa, comparable with the elastic modulus of natural bones, 3-30 $\mathrm{GPa}^{13}$. 


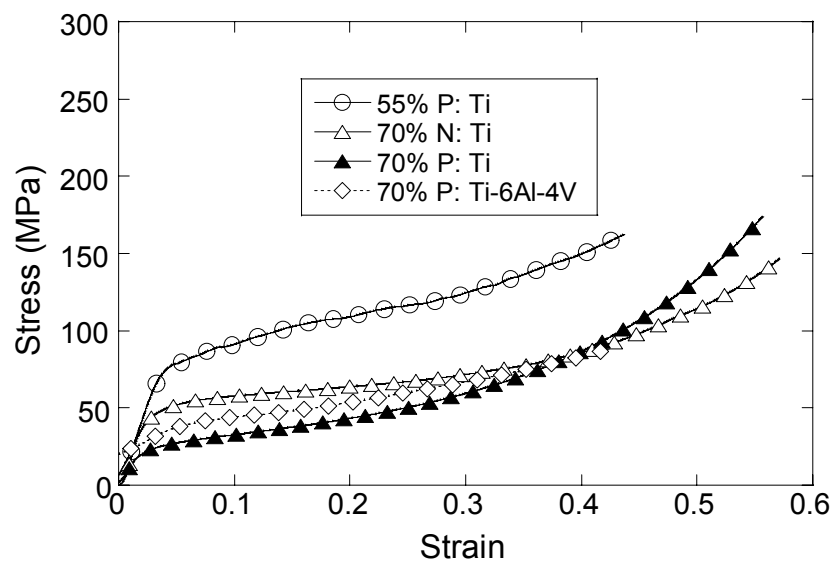

Figure 6. Compression stress-strain curves 60 and $70 \%$ porous Ti and Ti-6Al-4V foams.

The elastic modulus (E) and plateau stress $\left(\sigma_{\mathrm{pl}}\right)$ of open cell foams are usually predicted using the equations derived by Gibson and Ashby ${ }^{11}$ and given as

$$
\frac{\mathrm{E}}{\mathrm{E}_{\mathrm{s}}}=\alpha\left(\frac{\rho}{\rho_{\mathrm{s}}}\right)^{2}
$$

and

$$
\frac{\sigma_{\mathrm{pl}}}{\sigma_{\mathrm{ys}}}=\beta\left(\frac{\rho}{\rho_{\mathrm{s}}}\right)^{3 / 2}
$$

where $E_{\mathrm{s}}, \sigma_{\mathrm{ys}}, \rho_{\mathrm{s}}$ and $\rho$ are the elastic modulus, yield stress and density of cell wall material and density of foam, respectively. The values of constants, $\alpha$ and $\beta$, given in Eqns. 1 and 2 were experimentally determined to be 1 and 0.3 , respectively ${ }^{11}$. The modulus and collapse stress of $\mathrm{Ti}$ foams are predicted using above equations and the following appropriate material parameters: $\mathrm{E}=105 \mathrm{GPa}, \sigma_{\mathrm{ys}}=\sim 700 \mathrm{MPa}$ and $\rho=4.5 \mathrm{~g} \mathrm{~cm}^{-3}$. Fig. 7 a shows the predicted modulus values of Ti foam as function of percent porosity. In Fig. $7 \mathrm{a}$, the porosity range of $\mathrm{Ti}$ foam showing a good match with the elastic modulus of similar to that natural bones is found to be between 50 and $80 \%$ porosities. In the same range, Ti foam is predicted and experimentally shown to be stronger than the cancellous bone ${ }^{6}$ (Fig. 7b). This is beneficial for the handling and durability of the foam implants. It should be finally noted that Eqns. 1 and 2 are applicable for open cell foams with porosities higher than 
$70 \%$, therefore the predictions shown in Figs. $7 \mathrm{a}$ and $\mathrm{b}$ should be used with caution for lower values of porosities.

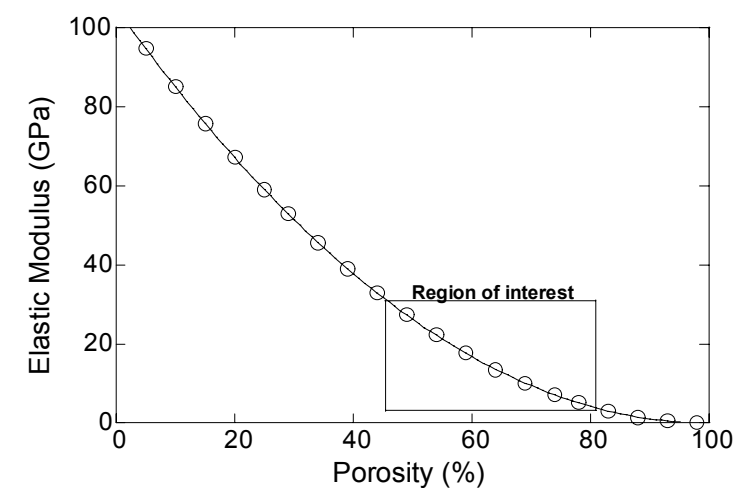

(a)

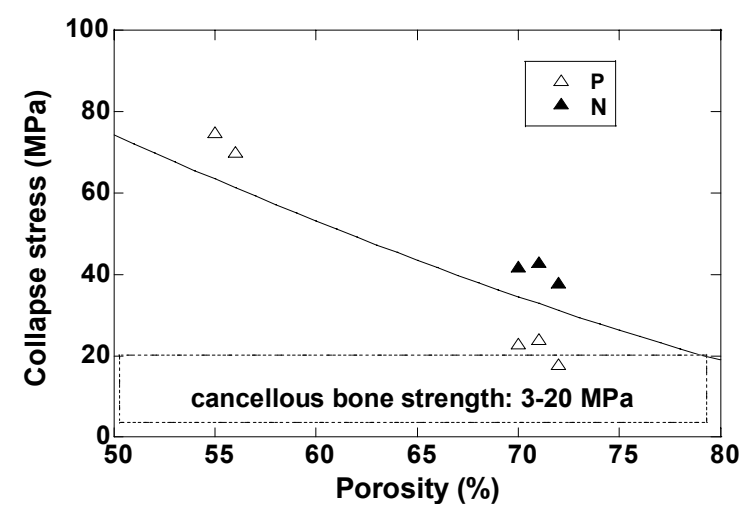

(b)

Figure 7. (a) Predicted elastic modulus and (b) predicted and experimental collapse stress values of $\mathrm{Ti}$ foam as function of percent porosity.

\section{CONCLUSION}

Foamed metals have many potential uses in biomedical applications including fully foamed implant components and coatings on solid implants and can be manufactured by the space holder method with relatively high porosity levels. In designing implant components with biocompatible metal foams several material aspects should, however, be considered including 
size, shape and level of porosity and mechanical properties. The geometry of cell in the final sintered foam metal results in direction dependent mechanical properties. The mechanical aspect includes two important properties of foamed metals; elastic modulus and plateau and/or collapse stress. The former is critical for the implant loosening and the latter for handling during implantation and durability in long term service. Since the foam properties are varied with the porosity level rather than with the cell wall material, the use of scaling relations allows the manufacture of designed structures for critical applications.

\section{ACKNOWLEDGEMENTS}

The authors would like to thank the Technology Development Foundation of Turkey (TTGV) for the grant \#TTGV-102/T13.

\section{REFERENCES}

1. Weiner, S., and Wagner, H. D.,1998, The material bone: structure-mechanical function relation. Annu. Rev. Mater. Sci. 28:271-298.

2. Pillar, R. M., 1987, Porous-surfaced metallic implants for orthopaedic applications. $J$. Biomed. Mater. Res. 21:1-3.

3. Banhart, J., 2001, Manufacture, characterisation and application of cellular metals and metal foams. Prog. Mater. Sci. 46:559-632.

4. Körner, C., and Singer, R. F., 2002, Processing of metal foams-challenges and opportunities. Adv. Eng. Mater. 2:159-165.

5. Martin, B., Stiller, C., Buchkremer, H. P., Stöver, D., and Baur, H., 2000, High purity titanium, stainless steel and superalloy parts . Adv. Eng. Mater. 2:196-199.

6. Wen, C. E., Mabuchi, M., Yamada, Y., Shimojima, K., Chino, Y., and Asahina, T., 2001, Processing of biocompatible porous Ti and Mg. Script. Mat. 45:1147-1153.

7. Wen, C. E., Yamada, Y., Shimojima, K., Chino, Y., Asahina, T., and Mabuchi, M., 2001, Processing and mechanical properties of autogenous titanium implant materials. J. Mater. Sci. 13:397-401.

8. Froes, F. H., 2002 Lightweight heavyweight, Metal Powder Report (www.metalpowder.net)

9. Clemow, A. J. T, Weinstein, A. M., Klawitter, J. J., Koeneman, J., and Anderson, J., 1981, Interface mechanics of porous titanium implants. J. Biomed. Mater. Res. 15: 73-82.

10. Chang, Y., Oka, M., Kobayashi, M., Gu, H., Li, Z., Nakamura, T., and Ikada, Y., 1996, Significance of interstitial bone ingrowth under load-bearing conditions: a comparison between solid and porous implant materials, Biomaterials 17: 1141-1148.

11. Gibson L. J., and Ashby F., 1997, Cellular solids: structure and properties. Cambridge University Press.

12. Elbir, S., Y1lmaz, S., Toksoy, K., Guden, M., and Hall, I. W., 2003, SiC-particulate aluminum composite foams produced by powder compacts: Foaming and compression behavior, J. Mater. Sci. 38:4745-4755.

13. Weiner, S., and Wagner, H. D.,1998, The material bone:structure-mechanical function relations. Annu. Rev. Mater. Sci. 28:271-298. 